\title{
Relações entre solo e fitofisionomias em florestas naturais ${ }^{1}$
}

\author{
Grasiele Dick ${ }^{2}$; Mauro Valdir Schumacher ${ }^{3}$
}

\begin{abstract}
Resumo: Esta revisão bibliográfica visa abordar os principais aspectos relacionados aos solos e a relação destes com os ecossistemas florestais, bem como a contextualização do componente edáfico, no âmbito físico, químico e biológico e apontar os resultados obtidos em diversas pesquisas neste contexto. O solo que ocorre sob floresta, apresenta características químicas e físicas diferenciadas de outros ambientes, onde a manutenção da fertilidade dar-se-á principalmente em função da ciclagem de nutrientes. De acordo com as condições do solo como nível de fertilidade, propriedades físicas, biológicas e até mesmo relevo e regime de umidade, pode-se verificar que há maior expressão de espécies ou até mesmo predomínio de uma tipologia florestal. No entanto, estas relações são estreitas e mais pronunciadas em nível de microescala, influenciadas expressivamente por diversos fatores relacionados ao sítio. Sendo assim, torna-se imprescindível incluir o máximo possível de variáveis ambientais a serem analisadas quando o objetivo é verificar as relações entre o tipo de solo e a vegetação. Ressalta-se à importância de abordagens mais amplas acerca do tema, com ênfase aos aspetos biológicos do solo, muitas vezes suprimidos nas abordagens científicas, bem como a incorporação de novos estudos.
\end{abstract}

Palavras - chave: Características edáficas; Ciclagem biogeoquímica; Nutrientes; Serapilheira.

\section{Relations between soil and phytophysiognomies in natural forests}

\begin{abstract}
This literature review aims to address the main aspects related to soils and their relation to forest ecosystems, and the contextualization of the edaphic component, in the physical, chemical and biological context, and to identify the results obtained in various studies in this context. The soil that occurs in forests, presents chemical and physical characteristics different from other environments where the maintenance of fertility will occur mainly as a function of nutrient cycling. According to the level of fertility of the soil, physical, biological and even topography and moisture regime conditions, it can be seen that there is greater expression of species or even a predominant forest type. However, these relations are narrow and more pronounced at the level of micro scale influenced significantly by various abiotic factors. So it is essential to include the maximum possible environmental variables to be analyzed when the scope and examine relationships between the type soil and vegetation. We emphasize the importance of broader approaches on the subject, with emphasis on biological aspects of soil, often suppressed in scientific approaches and eat the incorporation of new studies.
\end{abstract}

Keywords: Soil characteristics; Cycling biogeochemistry; Nutrients; Litter.

\footnotetext{
${ }^{1}$ Recebido em 12.01.2015 e aceito para publicação como artigo de revisão em 11.05.2015.

2 Engenheira Florestal; Doutoranda do Programa de Pós-graduação em Engenharia Florestal (UFSM). E-mail: <grasidick@hotmail.com>.

${ }^{3}$ Engenheiro Florestal, Dr. nat. techn., Professor Titular do Departamento de Ciências Florestais, Universidade Federal de Santa Maria. Email: <mvschumacher@gmail.com>.
} 


\section{Introdução}

Compreender a relação existente entre o solo e os ecossistemas é um subsídio imprescindível na tomada de decisão quanto ao manejo silvicultural e/ou estratégias de recuperação/restauração das mais diversas áreas. O solo atua como indicativo da tipologia florestal ocorrente na paisagem (SCHAEFER et al., 2012). No entanto, de acordo com Jenny (1941) a vegetação existente sobre um determinado sítio determinará, também, a composição do solo, influenciando principalmente no processo de transformação deste em função da adição de matéria orgânica proveniente da decomposição da serapilheira acumulada no piso florestal.

Um dos fatores mais importantes nas relações solo-planta está vinculado aos atributos químicos do solo, que exercem grande influência na ocorrência dos mais variados tipos de vegetação. A disponibilidade de nutrientes às plantas, que pode ser maior ou menor, pode estar relacionada principalmente aos aspectos físicos do solo, como por exemplo, a composição textural deste, resultante das ações químicas, físicas e biológicas do intemperismo (MEURER, 2007). A qualidade química do solo é enfatizada e amplamente abordada nos estudos que buscam detectar associações entre o solo e vegetação nos mais variados ambientes. Além deste fator, a biologia e a umidade do solo exercem um papel determinante na florística de um ecossistema, onde as plantas mais adaptadas têm êxito na ocupação de um sítio hidromórfico (JACOMINE, 2009), por exemplo.

Além de variáveis químicas, físicas e biológicas do solo, informações referentes ao relevo e conformação da floresta em relação à paisagem auxiliam na detecção de padrões de associação entre solo e vegetação (FERREIRA JUNIOR et al., 2012; SCIPIONI et al., 2010). No entanto, a percepção pode ser melhor expressada quando se considera uma abordagem em nível de microescala, onde as relações se manifestam de uma forma intrínseca, podendo assim obter respostas relevantes ao almejar a recomposição mais específica de áreas florestais degradadas.
Neste sentido, a presente revisão bibliográfica tem por objetivo abordar os principais aspectos envolvidos nas relações existentes entre o solo e a vegetação, enfatizando o papel do componente edáfico (físico, químico e biológico), bem como relatar alguns dos resultados de pesquisas realizadas neste âmbito. Sendo assim, será possível revelar as necessidades que ainda precisam ser supridas acerca do tema, bem como apontar direcionamentos para novas abordagens sobre as relações entre o solo e a vegetação.

\section{Desenvolvimento}

O papel do solo na sustentabilidade dos ecossistemas florestais

O solo tem como fator determinante de sua pedogênese o tipo de cobertura, como no caso a floresta, que possui um microclima sob o dossel que proporciona um espectro diferenciado de microrganismos, diferente da maioria dos solos sob outras coberturas (PRITCHETT e FISHER, 1987). Os solos sob os ecossistemas florestais são formados com influência da ação do desenvolvimento das raízes, atuação de organismos específicos associados à vegetação, presença de distintas camadas de serapilheira em diferentes estágios de decomposição, tendo como influência constante os fatores bióticos, como a presença de fauna e vegetação.

$\mathrm{O}$ solo atua como uma fonte de minerais e água à floresta (SILVA, 1996), sendo este o meio onde ocorrem etapas dos processos de ciclagem de nutrientes (SWITZER e NELSON, 1972), que se dá através da decomposição da matéria orgânica, proveniente do acúmulo de serapilheira (constantemente depositada pelo aporte vegetal). Este processo é responsável pela devolução dos minerais absorvidos pelas plantas ao solo, o que garante a manutenção da fertilidade e sustentabilidade nestes ecossistemas (POGGIANI, 2012; POGGIANI e SCHUMACHER, 2005). A presença da serapilheira também ameniza a temperatura das camadas superficiais do solo, otimizando assim a atividade biológica da fauna edáfica e demais 
microrganismos atuantes no processo de decomposição dos resíduos vegetais (KORASAKY et al., 2013).

As propriedades químicas do solo refletem, de maneira geral, a capacidade que determinado solo tem em fornecer nutrientes às plantas, ou seja, sua situação atual em termos de fertilidade, e indicam condições eutróficas ou distróficas do ambiente. A fertilidade e a umidade do solo geralmente ocorrem em gradientes negativos associados à sua profundidade, e isso pode limitar ou favorecer o desenvolvimento da vegetação, em função do nível de aptidão das mesmas. Em ecossistemas ripários, próximos ao curso d'água, as variabilidades químicas do solo podem ocorrer em virtude da ação do curso hídrico, através de fenômenos de lixiviação de nutrientes e carreamento de partículas de solo, e/ou depósito de sedimentos alóctones, e ainda outros fenômenos que distinguem esse tipo de ambiente (JACOMINE, 2009).

A qualidade química de um solo ainda é influenciada pelos fatores e processos de formação do solo, descritos em Jenny (1941), sendo que o tipo de vegetação também é determinante na gênese do solo. Considerando o fator material de origem pode-se observar diferenças entre solos formados sob basalto e arenito, que foram mencionadas na obra de Pritchett e Fisher (1987). Onde de uma forma geral, os solos florestais originados de granito apresentaram menor capacidade de troca de cátions e baixo conteúdo de matéria orgânica possuindo, no entanto, maiores teores de cálcio e magnésio quando comparados aos solos de origem basáltica.

Pedron e Dalmolin (2011), em estudo na região do Planalto Meridional do Rio Grande do Sul analisaram alguns perfis de solos florestais, com litologia predominante de basalto sob Floresta Estacional Subtropical secundária. Os autores classificaram os solos como sendo Neossolos, e verificaram que o Neossolo Regolítico era eutrófico, ou seja, apresentara maiores teores de macronutrientes (cálcio, magnésio e potássio), baixa saturação por alumínio e $\mathrm{pH}$ mais elevado, quando comparado ao Neossolo Litólico. Estas diferenças podem indicar que, sob mesmo tipo de cobertura, no caso a florestal, há variação de atributos químicos em função do grau de desenvolvimento do solo, condicionado pelo material de origem, fatores e processos de formação deste.

As propriedades físicas do solo influenciam de forma direta o crescimento e distribuição da vegetação, pois está intimamente associada à qualidade química e biológica do sítio (PRITCHETT e FISHER, 1987). A granulometria, expressa pelas frações argila, areia e silte, conforme a proporção que ocupam na composição do solo, condicionam maior ou menor fertilidade, em função dos argilominerais responsáveis pela retenção e disponibilização de nutrientes (MEURER, 2007). A regulação da drenagem e armazenamento de água no sistema solo também condiciona o crescimento de raízes, formação de agregados, entre outros (WILDE, 1958).

Quanto aos aspectos biológicos, os organismos que compõem a fauna edáfica estão intimamente associados à vegetação devido à influência na fertilidade do solo. Estes são capazes de cumprir funções ecológicas, atuando nos processos de decomposição e ciclagem de nutrientes, sendo que, posteriormente ocorre a mineralização e a humificação do material orgânico, que são de fundamental importância para a manutenção da produtividade dos ecossistemas naturais (CORREIA, 2002).

A diversidade da fauna está relacionada à permanência de resíduos orgânicos sobre a superfície do solo, que é expressiva em áreas florestais (ANTONIOLLI et al., 2006), atuando assim como bioindicadores da qualidade edáfica (LOUZADA e ZANETTI, 2013). Estes organismos influenciam os aspectos físicos do solo, pois são capazes de criar estruturas biogênicas, como túneis, canais, câmaras (KORASAKI et al., 2013), além de realizarem associações simbióticas, imprescindíveis para o crescimento e desenvolvimento da vegetação (MOREIRA e CAMPOS, 2013). De acordo com Puig (2008) as florestas naturais contêm grande biodiversidade de fauna edáfica, tanto que, após a sua retirada, a riqueza de organismos é reduzida drasticamente. 
Distinguindo ambientes através das relações entre o solo e a vegetação

A classificação do solo e suas relações com a vegetação remontam antes de Cristo com os chineses, conforme descrito em Gong et al. (2003). A percepção inicial existente entre a relação do solo com a vegetação ocorreu de forma associada à produtividade, e de acordo com o tipo de cobertura do solo.

Em estudo realizado sobre a origem e desenvolvimento da classificação do solo na China, um dos países pioneiros no assunto, os chineses iniciaram a classificação do solo no período da Dinastia Han (206 a.C. - 220 d.C.), analisando primeiramente as características morfológicas, considerando principalmente o aspecto mais perceptível, que era a cor e, então realizavam inferências de acordo com quantidade de alimento produzido, o tipo de vegetação ocorrente, a posição que a vegetação ocupava na paisagem e ainda, consideravam a umidade do solo para determinação da fertilidade (GONG et al., 2003).

No ocidente, as constatações iniciais se deram pelos índios da América do Norte e também pelas tribos Mongólias da Eurásia, que observaram uma nítida adaptação das plantas de acordo com o tipo de solo, avaliando a produtividade. Por dependerem diretamente da floresta, estes povos passaram a compreender os fatores que influenciavam a distribuição das árvores, arbustos, e todo tipo de vegetação que cobria o solo, associando à qualidade da madeira, casca e fibras, bem como a susceptibilidade das áreas ao fogo. Primordialmente, registros de estudos considerando a relação entre solo e nutrição vegetal datam desde a época de Aristóteles (322 - 384 d.C), depois Theophrastus (287 - 372 d.C) e, a relação entre solo e crescimento das árvores foi elucidada, de forma pioneira, por Cato (149 234 - d.C), Virgil (- 19 - 70 d.C) e Varo (27 116 - d.C) (WILDE, 1958).

No Brasil, os levantamentos pedológicos separaram os tipos de vegetação de acordo com as classes de solo, servindo assim como guia para detecção de sítios distintos. Com isso, expressou-se uma grande riqueza e variedade de relações edáficas e vegetacionais específicas conforme cada bioma brasileiro, em escala regional ou local, desde macroescala até escala de sítio (SCHAEFER et al., 2012).

Isto ocorre em decorrência das propriedades físicas, químicas e biológicas do solo, que influenciam a distribuição dos agrupamentos vegetais e das espécies na floresta (PUIG, 2008). As variações em função das condições edáficas podem ser detectadas, entretanto, ainda faltam informações de correlações específicas entre os diversos tipos de solos e as diversas variações das formações vegetacionais. Exemplos como a constatação do nível ótimo de umidade do solo em detrimento da aptidão, tolerância e desenvolvimento de espécies, bem como qual é a exigência nutricional requerida ao desenvolvimento de uma maior diversidade de espécies, em situações de locais degradados (JACOMINE, 2009).

A heterogeneidade florística associada à variação de condições ambientais, principalmente as relacionadas ao solo condicionam a coexistência de espécies vegetais, com diferentes exigências ecológicas. As diferenças quanto à composição e estrutura da comunidade florestal também são refletidas no solo (PINTO et al., 2008).

Em um fragmento de floresta nativa, no domínio da Mata Atlântica, Pinto et al. (2008) avaliaram duas áreas com presença de floresta, uma em estágio inicial de sucessão, onde a regeneração estava se estabelecendo em uma área destinada à pastagem, que estava isolada há 40 anos, e a outra um maciço florestal em estágio avançado de sucessão, bem preservado e sem interferência antrópica. Constataram que o solo sob a floresta em estágio inicial de sucessão é de baixa fertilidade, com maior porcentagem de areia, baixo teor de umidade e matéria orgânica, pH ácido, com elevada saturação por alumínio trocável e maior abertura do dossel, onde nesta situação ocorreram apenas 11 espécies, pertencentes à 10 famílias botânicas. Já na área de floresta madura, o solo é eutrófico, com maior porcentagem de silte, maior conteúdo de umidade e matéria orgânica, onde ocorreram 24 
espécies, compreendidas em 14 famílias.

Os referidos autores atribuem estas relações ao histórico de uso da área, onde a atividade de pastagem degradou o solo sendo que, as espécies que se desenvolveram nesta condição são de melhor adaptação às baixas disponibilidades nutricionais, como por exemplo Annona cacans, Trichilia pallida, Zanthoxylum rhoifolium, Matayba elaeagnoides. Já as espécies mais exigentes em fertilidade, ocorrentes na floresta madura, foram Nectandra lanceolata, Sorocea bonplandii, Cupania vernalis, Sapium glandulatum, dentre outras, especialmente àquelas pertencentes às famílias Sapindaceae, Euphorbiaceae, Fabaceae e Meliaceae.

Quanto à pesquisa sobre essas relações, Lescure e Boulet (1984) avaliaram a relação entre solo e vegetação em floresta tropical na Guiana Francesa. Os autores caracterizaram a influência de fatores edáficos sobre a cobertura florestal natural, usando mapas morfológicos e verificaram que a hidromorfia condiciona a seleção de espécies, bem como implica na variação em área basal das árvores. Já em Floresta Ombrófila Mista, Higuchi et al. (2012) encontraram correlações entre atributos químicos do solo, especialmente o $\mathrm{pH}$ e teores de magnésio, com a estrutura e composição florística em um fragmento, com maiores valores de importância das espécies Araucaria angustifola, Lithraea brasiliensis e Jacaranda puberula.

Em uma floresta na Amazônia colombiana, Calle-Rendón et al. (2011) avaliaram o solo e a estrutura florestal e também afirmam que a estrutura das florestas está associada aos fatores edáficos, sendo que há resposta da vegetação conforme a qualidade do sítio. Os autores verificaram estreita relação entre o nível de complexidade da vegetação e a textura do solo, sendo que, quanto mais arenosa a textura, mais completa e diversa se mostrou a estrutura vegetacional do estrato inferior da floresta.

No bioma Cerrado, Toledo et al. (2009) desenvolveram trabalhos com o objetivo de caracterizar esse ambiente, que ainda é pouco explorado em pesquisas, tendo como base qualificadores pedológicos e fitossociológicos.
Os autores avaliaram a vegetação em cinco ambientes distintos, sendo estes: duas áreas, em Neossolo Quartzarênico e Cambissolo Háplico, com predomínio da fração areia grossa no solo, onde a vegetação é típica do Cerrado stricto sensu, além de áreas mais conservadas, sendo uma destas um local de chapada em Latossolo, onde houve extração de madeira e queimadas intensas, outra chapada com plantio abandonado de eucalipto, entremeado com regeneração típica do Cerrado e a área de transição entre chapada e vereda.

Os referidos autores verificaram que os ambientes foram distinguidos em função dos aspectos geológicos, como material de origem (arenito-quartzito) e textura mais grosseira do solo (calhaus e matacões), pois os distintos reflexos se manifestaram no comportamento da vegetação em relação às áreas de chapada, que apresentaram maior densidade de indivíduos e maior índice de diversidade. No entanto, em contrapartida, nos locais com predomínio da fração areia houve maior área basal dos indivíduos, ou seja, maior produção volumétrica.

Em geral, nas áreas de Cerrado stricto sensu Toledo et al. (2009) concluíram que, os aspectos geológicos, litologia e natureza dos sedimentos, bem como parâmetros florísticos e fitossociológicos de densidade absoluta, área basal e o índice de diversidade, além das frações granulométricas, foram atributos determinantes na diferenciação dos ambientes.

Na região sudeste, no estado de São Paulo, Rossi et al. (2005) em área de transição cerradofloresta e Ruggiero et al. (2006) em fragmento de Floresta Estacional Semidecidual, realizaram estudos em ambientes ripários, próximos aos cursos hídricos, e verificaram relação da hidromorfia com a caracterização da vegetação, que se desenvolve melhor em ambientes bem drenados. De acordo com Puig (2008), podemse distinguir os agrupamentos vegetais em relação direta com a maior ou menor saturação da água do solo, pois formações florestais, submetidas à saturação permanente ou temporária do solo, são distintas florística e estruturalmente, em comparação ao solo bem drenado. 
Em Floresta Estacional Subtropical, no bioma Mata Atlântica, Almeida (2010) avaliou a formação de agrupamentos de vegetação arbustiva e arbórea, conforme as características de declividade do terreno e de solo (capacidade de troca de cátions, teor de argila, acidez trocável). Foi detectada a presença de espécies indicadoras, formando dois grupos de acordo com as características do solo, correlacionadas estas à capacidade de troca de cátions, teor de argila, acidez trocável, variando conforme a declividade. Na mesma tipologia, Dullius (2012) realizou estudo no Rebordo do Planalto do Rio Grande do Sul, no município de Itaara, em dois níveis diferentes de sucessão (floresta secundária e capoeira), onde verificou que as espécies distribuem-se em função da variação dos atributos pedológicos, condicionados principalmente pelo relevo da área.

No entanto, ao avaliar uma topossequência, Scipioni et al. (2011), verificaram que a qualidade química e granulometria do solo não influenciaram de forma significativa a distribuição e abundância de espécies, mas sim houve influência da declividade e do grau de desenvolvimento do solo. Dullis (2012) afirma que as associações entre a distribuição das espécies e gradiente ambientais só podem se tornar verdadeiros após a repetição do mesmo padrão em diversas áreas.

Em relação aos aspectos biológicos do solo, de acordo com Ferreira et al. (2013), o sistema serapilheira-solo compreende o substrato necessário para a grande parte da biodiversidade em ecossistemas florestais. A macro, meso e microfauna tem papel importante na manutenção da biodiversidade dos ecossistemas naturais, desempenhando funções importantes à manutenção de fertilidade do solo, seja pela adição e decomposição da matéria orgânica, associações simbióticas, relações sinérgicas e antagônicas, dentre outras contribuições.

Para a floresta tropical úmida, Puig (2008) relata a presença de grupos dominantes na fauna do solo, onde formigas, térmitas, coleópteros, minhocas e miriápodes são expressivos, principalmente na interface solo/serapilheira. $\mathrm{O}$ autor ainda menciona aspectos ligados à biomassa de fauna nesta fitofisionomia, com maior densidade de microartrópodes (70.000 ind $\mathrm{m}^{-2}$ ) em comparação à área de savana (38.000 ind $\mathrm{m}^{-2}$ ), peso fresco de macrofauna na amplitude de 36 a $96 \mathrm{~g} \mathrm{~m}^{-2}$, sendo que, as minhocas representam de $49 \%$ a $91 \%$ da massa total, sendo estas fundamentais na degradação da matéria orgânica. As formigas, organismos muito importantes para a decomposição da serapilheira, são as mais abundantes, no entanto, representam de $1,1 \%$ a $7,1 \%$ da biomassa.

$\mathrm{O}$ autor supracitado ainda menciona que a macrofauna é mais diversa em áreas de floresta tropical úmida madura quando se compara às áreas de capoeira, savana e pastagem. Por exemplo, em uma floresta na Guiana Francesa há maior número de indivíduos e mais biomassa de fauna, quando comparada a uma área de capoeira, onde há expressividade de predadores como grilos, aranhas e hemípteras. Além da influência do tipo vegetacional sobre a fauna, o solo também pode afetar a velocidade de decomposição de resíduos, uma vez que em solos bem drenados a velocidade de degradação de tecidos foliares é mais acelerada quando comparada a sítios hidromórficos, que implicam em condições anaeróbicas.

Variações em função do solo são detectadas, entretanto, faltam informações de correlações específicas entre os diversos solos e as diversas variações das formações específicas ocorrentes nessas situações. Jacomine (2009) recomenda que sejam feitos estudos de correlação aprofundadas entre as diversas classes de solo e respectivas formações florestais, com destaque à ocorrência de espécies indicadoras.

\section{Considerações finais}

Vários trabalhos estão sendo realizados acerca do tema das relações entre solo e vegetação, no entanto, em função de especificidade dos estudos, os resultados não podem ser extrapolados ou generalizados para os mais variados ambientes.

Em função da extensão territorial, a diversidade existente entre tipologias florestais e 
até mesmo em nível de bioma é decorrente das condições climáticas e edáficas totalmente diferenciadas. Até mesmo a exigência nutricional e ambiental das mais variadas espécies florestais varia de acordo com a região geográfica em que se encontram, sendo assim, não é possível a padronização de comportamentos quanto à distribuição, composição florística e estrutural da vegetação.

Abordagens mais amplas acerca do tema, incorporando-se novos estudos, com ênfase principalmente nos aspectos intrínsecos à biologia do solo, nos mais variados ecossistemas florestais, bem como, a utilização adequada das informações geradas nestas pesquisas podem subsidiar de uma forma mais concisa a tomada de decisões sobre o manejo de áreas florestais.

$\mathrm{O}$ uso de metodologias e análises mais precisas, inclusão do maior número possível de variáveis que possam ser explicativas dos reflexos das relações entre o solo e a vegetação, são quesitos que podem vir a ampliar a compreensão destas interações entre vegetação e o componente solo, que são consideradas complexas.

\section{Referências Bibliográficas}

ANTONIOLLI, Z. I.; et al. Método alternativo para estudar a fauna do solo. Ciência Florestal, Santa Maria, v. 16, n. 4, p. 407-417, 2006.

\section{ALMEIDA, C. M. Relação solo-fitossociologia em um remanescente de Floresta Estacional Decidual. 2010. 74 f. Dissertação (Mestrado em Engenharia Florestal) - Universidade Federal de Santa Maria, Santa Maria. 2010.}

CALLE-RENDÓN, B. R.; MORENO, F.; CÁRDENAS-LÓPEZ, D. Relación entre suelos y estructura del bosque en la Amazonía colombiana Rev. Biol. Trop. v. 59, n 3. P. 1307 1322, 2011.

CORREIA, M. E. F. Potencial de utilização dos atributos das comunidades de fauna do solo e de grupos chave de invertebrados como bioindicadores de manejo de ecossistemas. Seropédica, Embrapa Agrobiologia, 2002. 23p.

DULLIUS, M. Vegetação e solos de uma Floresta Estacional do Rio Grande do Sul. 2012. 127 f. Dissertação (Mestrado em Engenharia Florestal) - Universidade Federal de Santa Maria, Santa Maria, 2012.

FERREIRA JUNIOR, W. G.; SCHAEFER, C. E. G. R.; SILVA, A.F. Uma visão pedogeomorfológica sobre as formações florestais da Mata Atlântica. In: MARTINS, S.V. (Org). Ecologia de Florestas Tropicais no Brasil. Viçosa, MG. Ed.: UFV, 2012. 371 p.

FERREIRA. K. L.; et al. Inter-relação entre componentes biológicos e fatores ambientais no sistema serapilheira-solo sob diferentes coberturas vegetais. In: Anais... V Congresso Fluminense de iniciação científica e tecnológica. Campos dos Goytacazes, RJ. 2013.

GONG, Z.; et al. Origin and development of soil science in ancient China. Geoderma. v. 115, p 3-13, 2003.

HIGUCHI, P.; et al. Influência de variáveis ambientais sobre o padrão estrutural e florístico do componente arbóreo, em um fragmento de Floresta Ombrófila Mista Montana em Lages, SC. Ciência Florestal, Santa Maria, v. 22, n. 1, p. 79-90, 2012.

JACOMINE, P. K. T. Solos sob matas ciliares. In: RODRIGUES, R. R.; LEITÃO FILHO, H. de F. (eds) Matas ciliares: conservação e recuperação. São Paulo: Editora da Universidade de São Paulo, Fapesp, 2009, p. 4571.

JENNY, H. Factors of soil formation. A System of Quantitative Pedology. New York: McGraw-Hill, 1941. 281 p.

KORASAKI, V. et al. Macrofauna. In: In: MOREIRA, F. M. S. et al. O ecossistema solo: 
componentes, relações ecológicas e efeitos na produção vegetal. Lavras, Ed. UFLA, 2013. $352 \mathrm{p}$.

LESCURE, J. P.; BOULET, R. Relationships between Soiland Vegetation in a Tropical Rain Forest in French Guiana. Biotropica. v. 17, n. 2. p 155-164. 1985.

LOUZADA, J.; ZANETTI, R. Bioindicadores de impactos ambientais. In: In: MOREIRA, F. M. S. et al. O ecossistema solo: componentes, relações ecológicas e efeitos na produção vegetal. Lavras, Ed. UFLA, 2013. 352 p.

MEURER, E. J. Fatores que influenciam o crescimento e desenvolvimento das plantas. In: NOVAIS, R. F.; et al., (eds). Fertilidade do solo. $1^{\text {a }}$ ed. Viçosa/MG, Sociedade Brasileira de Ciência do Solo, 2007. p.65-90.

MOREIRA, F. M. S.; CAMPOS, C. R. A. Micro-organismos. In: MOREIRA, F.M.S. et al. O ecossistema solo: componentes, relações ecológicas e efeitos na produção vegetal. Lavras, Ed. UFLA, 2013. 352 p.

PEDRON, F. A.; DALMOLIN, R. S. D. Solos da região do rebordo do Planalto Meridional no Rio Grande do Sul. In: SCHUMACHER, M. V.; et al. (eds). A Floresta Estacional Subtropical: caracterização e ecologia no rebordo do Planalto Meridional. Santa Maria, 2011, 320 p.

PINTO, S. I. C. et al. Influence of environmental variables on the shrub and tree species distribution in two Semi-deciduous Forest sites in Viçosa, Minas Gerais, Brazil. Revista de Biología Tropical, v.56, n.3, p. 1557-1569, 2008.

POGGIANI, F. Ciclagem de nutrientes em Florestas do Brasil. In: MARTINS, S.V.; et al. Sucessão Ecológica: Fundamentos e Aplicações na Restauração de Ecossitemas Florestais. In: MARTINS, S. V. (Org). Ecologia de Florestas Tropicais no Brasil. Viçosa, MG. Ed.: UFV, 2012. p371.
POGGIANI, F.; SCHUMACHER, M. V. Ciclagem de nutrientes em florestas nativas. In: GONÇALVES, J. L. M.; BENEDETTI, V. Nutrição e Fertilização Florestal. Piracicaba: IPEF, 2005, 427p.

PRICHTETT, W. L.; FISHER, R. Properties and management of forest soil. $2^{\text {nd }} \mathrm{ed}$. Nova York: John Wiley \& Sons, 1987. 488 p.

PUIG, H. A Floresta Tropical Úmida. São Paulo-Editora UNESP, 2008. 493 p.

ROSSI, M.; et al. Relação Solos/Vegetação em Área Natural no Parque Estadual Porto Ferreira, São Paulo. Rev. Inst. Flor., São Paulo, v. 17, n. 1, p. 45-61. 2005.

RUGGIERO, P. G. C.; et al. Relação entre solo, vegetação e topografia em área de cerrado (Parque Estadual de Vassununga, SP): como se expressa em mapeamentos? Acta bot. bras. v. 20, n. 2, p. 383-394. 2006.

SCIPIONI, M. C.; et al. Distribuição do compartimento arbóreo em gradiente de relevo e solos na encosta Meridional da Serra Geral, RS. Ciência Rural, Santa Maria, v.40, n.6, p. 12951301. 2011.

SCHAEFER, C. R. G. R.; et al. Relações Solovegetação em Alguns Ambientes Brasileiros: Fatores edáficos e florística. In: MARTINS, S.V. (Org). Ecologia de Florestas Tropicais no Brasil. Viçosa, MG. Ed.: UFV, 2012. 371 p.

SILVA, L. F. Solos tropicais - aspectos pedológicos, ecológicos, ecológicos e de manejo. São Paulo: Brasilis Editora, 1996. $137 \mathrm{p}$.

SWITZER, G. L.; NELSON, L. E. Nutrient accumulation and cycling in Loblolly Pine (Pinus taeda) plantation ecosystems: The first 20 years. Soil Sci. Soc. Am. Pro. v. 36, p. 143-147, 1972. 
TOLEDO, L. O.; et al. Análise multivariada de atributos pedológicos e fitossociológicos aplicada na caracterização de ambientes de Cerrado no norte de Minas Gerais. Revista Árvore, Viçosa, MG, v.33, n.5, p. 957-968, 2009.

WILDE, S. A. Forest soils: their properties and relation to silviculture. New York: The Ronald Press Company, 1958. 536 p. 